\title{
På St. Olavs hospital beroliges barn med nesespray $f ø r$ plagsomme prosedyrer
}

Prosedyrer som blodprøvetaking og sårskift blir mindre smertefulle for barn når de får en lettere sedering administrert som nesespray .

\section{Forfatter}

\section{Lisa Hugdahl}

Seksjonsleder

Barn intensiv, St. Olavs hospital

\section{Nøkkelord}

Barn Intensiv sedasjon intranasal premedikasjon

Sykepleien 2018 106(70698)(e-70698)

DOI: https://doi.org/10.4220/Sykepleiens.2018.70698

\section{HOVEDBUDSKAP}

Med denne artikkelen ønsker vi å fremme en trygg prosedyresedering med dexmedetomidin, administrert intranasalt.

Legemiddelet blir først og fremst benyttet til barn og unge for å lindre angst og smerte, slik at barnet er rolig og samarbeidende når det skal legges inn perifer venekanyle, tas blodprøver, ved CT- eller MR-undersøkelse, ved sårskift, fjerning av ulike typer katetre samt premedikasjon.

Fordelene med nesespray er at man får gitt medikamentet uten intravenøs inngang, og man får en rask effekt når medikamentet gis nasalt ved at det blir tatt opp direkte i blodbanen. 
Dexmedetomidin er et kjent medikament på

intensivavdelingene, som brukes til sedasjon samt for å redusere abstinens ved nedtrapping av annen sedasjon. Sedasjon med dexmedetomidin, administrert som nesespray (intranasalt), brukes før prosedyrer eller som premedikasjon hos barn og unge. Medikamentet er et godt alternativ til legemiddelet Midazolam som ofte ble administrert til barnet gjennom munnen (per os).

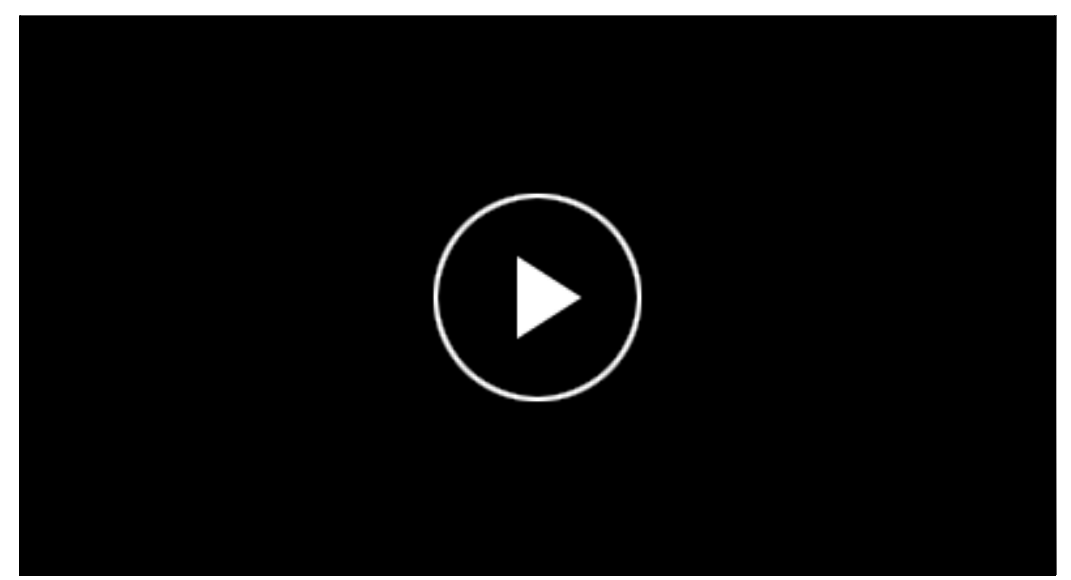

INTRANASAL PROSEDYRESEDERING: Slik brukes nesesprayen i praksis. Filmen viser mor Hanne Hansen sammen med sin sønn Oliver, som blir sedert før en operasjon. Film: Lena Knutli

Siden 2015 har vår avdeling, Barn intensiv, og flere seksjoner ved Barne- og ungdomsklinikken (BUK) på St. Olavs hospital benyttet dexmedetomidin administrert i nesespray. Fra mars 2016 til mars 2017 ble all bruk av dexmedetomidin intranasalt ved BUK registrert.

\section{Forberedelser}

Studier har vist flere fordeler med dexmedetomidin, både som premedikasjon og som sedasjon ved prosedyrer (1-8). En fordel med å gi dexmedetomidin som nesespray til barn er at en får gitt medikamentet uten intravenøs inngang. Man får også en rask effekt når medikament gis nasalt ved at det blir tatt opp direkte i blodbanen. 
I tillegg er dexmedetomidin et medikament som er trygt å bruke som beroligende medikasjon (sedasjon) med tanke på respirasjonsdepresjon. Hensikten med å sedere i forbindelse med prosedyrer hos barn og unge er generelt å lindre angst og smerte samt å redusere uønskede bevegelser, slik at barnet er rolig og samarbeidende.

\section{三 «Informasjonen må være tilpasset barnets alder og utvikling.»}

Barn og unge som er innlagt på sykehus, skal ofte gjennom flere undersøkelser og prosedyrer. Noen kan være mer skremmende enn andre, og god forberedelse og informasjon er viktig, uansett hvor stor eller liten prosedyre barnet skal gjennom.

LES: Lindrer prosedyresmerte med nesespray

Informasjonen må være tilpasset barnets alder og utvikling. Sykepleier og lege som informerer om og/eller utfører prosedyren, må først opparbeide tillit og trygghet hos både barn og foreldre. Barnet blir i stor grad påvirket av foreldrenes trygghet i situasjonen. Samspillet mellom barn, foreldre og helsepersonell er av stor betydning for å lykkes med de oppgavene som skal utføres.

\section{Utvide bruken}

Medikamenter brukt til sedasjon har bieffekter som opplevd tap av kontroll, hukommelsestap (amnesi) og abstinens etter langvarig bruk. Det er ikke påvist at dexmedetomidin gir amnesi. Det stilles også spørsmål ved om det er gunstig for barn å oppleve amnesi (8). 
I en oppsummering etter å ha brukt dexmedetomidin intranasalt i snart tre år ved Barne- og ungdomsklinikken ved St. Olavs hospital ser vi at det er ønskelig å utvide bruken til flere prosedyrer og flere pasientgrupper ved klinikken. Dette kan kanskje være starten på en liten revolusjon når det gjelder lette sederinger der pasienten ikke trenger dyp søvn og smertelindring (analgesi).

\section{Egenskaper}

Dexmedetomidin er som Klonidin, en $\alpha_{2}-$ reseptoragonist med sedative, analgetiske og sympatikushemmende egenskaper. Dexmedetomidin er en mer spesifikk $\alpha_{2}$-agonist enn Klonidin, og halveringstiden er mye kortere, det vil si 2-3 timer mot 12-24 timer.

Medikamentet absorberes godt i slimhinnen (god biotilgjengelighet) etter administrering i nesen (65 prosent) (5, 6). Biotilgjengeligheten i munnhulen, når man sprayer mot kinnet (buccalt), er meget god, men studier av dexmedetomidin administrert nasalt og buccalt til barn viser at det er vanskeligere å få gitt riktig dose buccalt. Når medikamentet gis i munnen og ikke blir absorbert via munnslimhinnen, vil den minste uro hos barnet føre til at medikamentet renner ned $\mathrm{i}$ svelget (2).

Oral bruk av dexmedetomidin gir dårlig biotilgjengelighet, det vil si at medikamentet svelges og blir tatt opp via magesekken (16 prosent) $(4,5)$. Dexmeditomidin metaboliseres i lever (glukuronidering) og utskilles i urin $(4,5)$.

\section{Bivirkninger}


Den vanligste bivirkningen er bradykardi. En reduksjon i hjertefrekvens med cirka 30 prosent etter administrasjon kan forventes. De barna som fikk bradykardi etter administrering av dexmedetomidin intranasalt, utviklet ikke hypotensjon, og blodtrykket holdt seg innenfor normalverdi. Bradykardien ble derfor ikke behandlet, og den lave hjertefrekvensen ble ikke oppfattet som alvorlig (5). Etter at man i studier ikke avdekket noen alvorlig bradykardi, anbefales overvåking av hjerterytme kun til barn under seks måneder og til de som har en kjent sirkulasjonssvikt (5).

Dexmedetomidin gir lite eller ingen respirasjonspåvirkning, og det er ikke observert alvorlig respirasjonsdepresjon selv etter aksidentell overdose (5, 6). Barnet kan tilføres mer medikament enn kroppen klarer å skille ut (akkumulasjon), noe som er vanlig ved langvarig sedasjon av barn, men ikke et problem ved engangsdosering.

\section{Nasal administrering}

Slimhinnen i nesehulen har en stor absorpsjonsevne med en god blodgjennomstrømning. Medikamentet blir tatt opp direkte i blodbanen, noe som gir et raskt opptak av medikamentet og en høy plasmakonsentrasjon etter kort tid. Det er viktig at legemiddelet gis konsentrert siden nesehulen kun tar opp et mindre volum av gangen. Ved å gi et konsentrert medikament vil man oppleve en raskere virkning.

Det er flere medikamenter som benyttes til sedasjon og smertelindring, som egner seg for nasal bruk. Antidot kan også gis nasalt.

Dexmedetomidin kan administreres intranasalt uten at det gir svie, og det oppfattes som smakløst. Ved premedikasjon er anbefalt dose $2-3 \mu \mathrm{g} / \mathrm{kg}$, mens det for prosedyresedering ofte vil være nødvendig med en større dose, $4-5 \mu \mathrm{g} / \mathrm{kg}$. 


\section{三 «Nesehulen har en stor absorpsjonsevne med en god blodgjennomstrømning.»}

Det er flere studier på nasal dexmedetomidin som premedikasjon, hvor man har sett på både dose og respons (1-8). Studiene viser at en større dose dexmedetomidin vil gi raskere anslag. Det er ikke rapportert noen paradoksal reaksjon ved nasal dexmedetomidin som premedikasjon, det vil si det motsatte av det vi ønsker, og som vi av og til ser ved bruk av Midazolam. Anslagstiden er 20-30 minutter og virketiden 1-3 timer. Dette er mye raskere enn tidligere antatt og gir et større bruksområde $(4,5)$.

For smertefulle prosedyrer kan dexmedetomidin kombineres med opioider, men dette forutsetter overvåkning med pulsoksymeter. Det samme gjelder for barn og unge med påvirkede vitale funksjoner (respirasjon, sirkulasjon, bevissthet) samt barn under seks måneders alder.

\section{Praktisk fremgangsmåte}

Dexmedetomidin finnes som Dexdor $100 \mu \mathrm{g} / \mathrm{ml}$ injeksjonsvæske i ampuller à $2 \mathrm{ml}=200 \mu \mathrm{g}$. Et forstøverforstykke LMA MAD Nasal (se foto) settes på en $1 \mathrm{ml}$ injeksjonssprøyte, og det definerte volumet dusjes opp i neseslimhinnen på samme måte som vanlig nesespray. Barnet kan sitte eller ligge ved administrasjon av legemiddelet. 


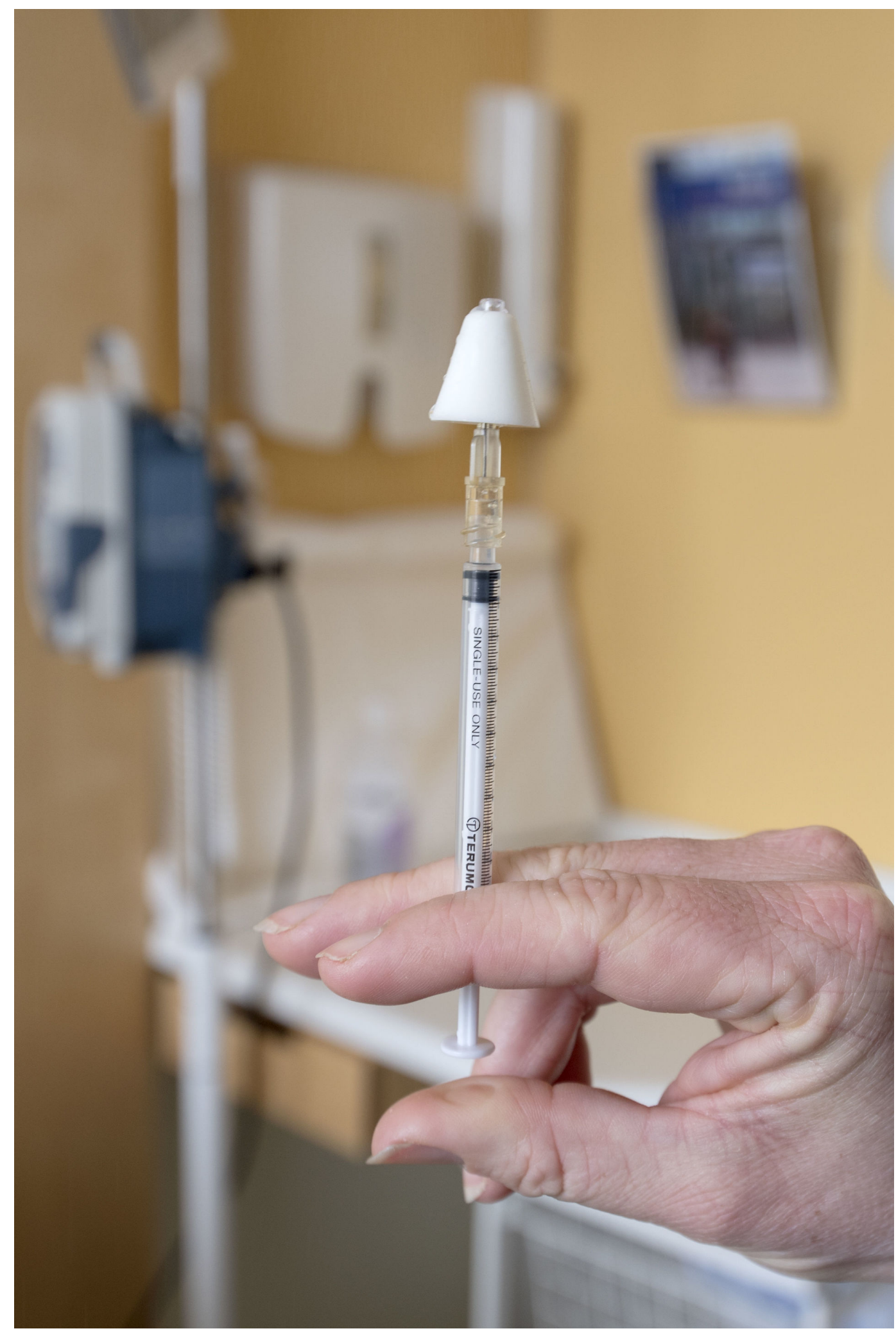

INTRANASAL ADMINISTRERING: Et forstøverforstykke settes på en $1 \mathrm{ml}$ injeksjonssprøyte, og det definerte volumet dusjes opp i neseslimhinnen på samme måte som vanlig nesespray. Foto: Lena Knutli 
Dosene skal gis i mindre deler, helst $0,1-0,3 \mathrm{ml}$, men maks $0,5 \mathrm{ml}$ til store barn. $\mathrm{Vi}$ anbefaler å bytte nesebor før hver nye dose. Ved større doser bør det gå litt tid mellom hver dusj, men det er ikke nødvendig å vente flere minutter. Merk at sprayforstykket har et «dødvolum» på 0,1 ml (= $10 \mu \mathrm{g})$. Total dose bør ikke overstige $300 \mu \mathrm{g}$, uansett kroppsvekt.

\section{Erfaringer}

Siden 2015 har vår avdeling og flere seksjoner ved Barne- og ungdomsklinikken (BUK) på St. Olavs hospital benyttet dexmedetomidin intranasalt. Sammen med medikamentet og det nasale forstøverstykket ble det sendt med et evalueringsskjema til alle sykepleiere som skulle benytte legemiddelet.

Vi fikk inn totalt 81 evalueringsskjema. Det var 28 jenter og 53 gutter som hadde fått legemiddelet. Nitti prosent av respondentene svarte at det er enkelt å administrere dexmedetomidin intranasalt. Ved spørsmål om effekten var tilfredsstillende, svarte 85 prosent av sykepleierne som ga legemiddelet til barna, at det var god effekt, 20 prosent sa at legemiddelet ga lite eller ingen effekt, og 2 prosent svarte at barnet ble tungt sedert / overdosert.

Noen sykepleiere krysset av for både god effekt og lite eller ingen effekt. Kun fem barn og unge fikk en ny dose eller et annet medikament i tillegg. Når vi analyserte registreringene, så vi at tilbakemelding på lite eller ingen effekt stort sett gjaldt de største barna. Vi hadde en mistanke om at grunnen til at medikamentet ga lite effekt, mest sannsynlig hadde med måten medikamentet ble administrert på. Som en konsekvens ble oppmerksomheten rundt opplæring større ved utdeling av medikamentet.

\section{三 «Grunnen til at medikamentet ga lite effekt, hadde mest sannsynlig med måten medikamentet ble administrert på.»}


Studier har vist at yngre barn, fra seks måneders alder til tre år, har bedre effekt av dexmedetomidin intranasalt. Det må gjøres mer forskning før vi kan konkludere med om det er riktig administrasjonen eller mengden av legemiddelet som er avgjørende $(3,8)$.

I begynnelsen ble ikke alle sykepleierne gjort oppmerksomme på hvor stor dose av legemiddelet som kan settes i hvert nesebor. Det ble derfor gitt en for stor dose i hvert nesebor, noe som medførte at deler av medikamentdosen rant bak i svelget.

I tillegg er det viktig med et fast trykk på stempelet så medikamentet blir forstøvet og ikke renner ned langs sprøyten eller bak i svelget. Korrekt administrasjon er helt avgjørende for at barnet skal få god virkning av legemiddelet. Opplæring ved utdeling av medikamentet samt internundervisninger ble innført ved de fleste seksjonene ved BUK.

\section{Rolige omgivelser}

Nøye vurdering av hva pasienten har behov for når en prosedyre skal utføres, er vesentlig. Det er også viktig å avklare om medikamentet kun skal benyttes som premedikasjon. Er det søvn, sedering og/eller analgesi vi er ute etter?

Barnet blir ikke tungt sedert med intranasalt dexmedetomidin, men det oppnår en god søvn. Dexmedetomidin er ulikt andre sedativer i og med at det opprettholder REM-søvn (4, 5). Barnet sover dypt, men er lett å vekke og faller lett tilbake i søvn uten stimuli. Barnet må derfor informeres og forberedes godt på prosedyren som skal gjennomføres.

\section{三 «Hvis man ønsker dyp søvn, er det viktig at barnet ikke blir forstyrret.»}


Det er viktig med rolige omgivelser fra alle som er rundt pasienten, da vi ser at mange reagerer på lyd og lett manipulasjon. Etter at medikamentet er gitt, vil barnet sovne etter cirka 30 minutter, og hvis man ønsker dyp søvn, er det viktig at barnet ikke blir forstyrret. Det kan være en fordel å stimulere kroppsdelen der den aktuelle prosedyren skal utføres, når barnet sovner, så barnet ikke våkner brått ved berøring når prosedyren skal utføres.

\section{Bruksområder}

Fra evalueringsskjemaene ser vi at nasal dexmedetomidin først og fremst har blitt benyttet når det skal legges inn perifer venekanyle (PVK), tas blodprøver, ved CT- eller MR-undersøkelse, ved sårskift, fjerning av ulike typer katetre samt premedikasjon. Legemiddelet ble også brukt til sondenedleggelse, noe som ikke alltid var vellykket, da barnet våknet under prosedyren.

Med denne artikkelen ønsker vi å fremme en trygg bruk av dexmedetomidin intranasalt. Med nye prosedyrer, der vi skiller mellom sedering før prosedyrer og sedering for premedikasjon, og ved å gi god undervisning og opplæring til personalet, håper vi at flere pasienter ved BUK kan få tilbud om sedering ved bruk av nesespray.

\section{Referanser}

1. Akin A, Bayram A, Esmaoglu A, et al.

Dexmedetomidine vs midazolam for premedication of pediatric patients undergoing anesthesia. Ped Anesth. 2012;10:1-6.

2. Cimen ZS, Hanci A, Sivrikaya GU, et al. Comparison of buccal and nasal dexmedetomidine premedication for pediatric patients. Ped Anesth. 2013;23:134-8. 
3. Li BL, Ni J, Huang JX, et al. Intranasal dexmedetomidine for sedation in children undergoing transthoracic echocardiography study - a prospective observational study. Ped Anesth. 2015;25:891-6.

4. Mahmoud M, Mason KP. Dexmedetomidine: review, update, and future considerations of paediatric perioperative and periprocedural applications and limitations. Br J Anaesth. 2015;115:171-82.

5. Mason KP, Lerman J. Dexmedetomidine in children: current knowledge and future applications. Anesth Analg. 2011;113:1129-42.

6. McMorrow SP, Abramo TJ.

Dexmedetomidine sedation uses in pediatric procedural sedation outside the operating room. Ped Emerg Care. 2012;28:292-9.

7. Wang SS, Zhang MZ, Sun Y, et al. The sedative effects and the attenuation of cardiovascular and arousal responses during anesthesia induction and intubation in pediatric patients: a randomized comparison between two different doses of preoperative intranasal dexmedetomidine. Ped Anesth. 2014;24:275-81.

8. Yuen VM, Hui TW, Irwin MG, et al. A comparison of intranasal dexmedetomidine and oral midazolam for premedication in pediatric anesthesia: a double-blinded randomized controlled trial. Anesth Analg. 2008;6:1715-21. 